\title{
Selective Knockdowns in Maize by Sequence-Specific Protein Aggregation
}

\author{
Camilla Betti, Joost Schymkowitz, Frederic Rousseau, \\ and Eugenia Russinova
}

\begin{abstract}
Protein aggregation is determined by $5-15$ amino acids peptides of the target protein sequence, so-called aggregation-prone regions (APRs) that specifically self-associate to form $\beta$-structured inclusions. The presence of APRs in a target protein can be predicted by a dedicated algorithm, such as TANGO. Synthetic aggregation-prone proteins are designed by expressing specific APRs fused to a fluorescent carrier for stability and visualization. Previously, the stable expression of these proteins in Zea mays (maize) has been demonstrated to induce aggregation of target proteins with specific localization, such as the starchdegrading enzyme $\alpha$-glucan water dikinase, giving rise to plants displaying knockdown phenotypes. Here, we describe how to design synthetic aggregation-prone proteins to harness the sequence specificity of APRs to generate aggregation-associated phenotypes in a targeted manner and in different subcellular compartments. This method points toward the application of induced targeted aggregation as a useful tool to knock down protein functions in maize and to generate crops with improved traits.
\end{abstract}

Key words Protein interference, Sequence-specific aggregation, APR, Protein knockdown technology, $\beta$-sheet inclusions

\section{Introduction}

The global demand for transgenic crops with a high commercial value continuously requires the development of new technologies that are able to circumvent disadvantages or failures of the existing ones. Therefore, a new protein knockdown technology, referred to as protein interference $(\mathrm{Pi})$, initially elaborated in the model species Arabidopsis thaliana was further transferred into maize (Zea mays) [1]. The Pi technology allows obtaining maize knockdown mutants with a high specificity by inducing a target protein misfolding and aggregation. During the folding process, newly synthesized peptide sequences may take several paths, leading to proper or incorrect protein folding. Misfolded or unfolded proteins can aggregate in insoluble agglomerates [2]. The proposed method is based on the 
fact that protein aggregation is mediated by hydrophobic betastructured interactions in short aggregation-prone segments of polypeptide chains that become exposed upon misfolding, leading to their association into intermolecular aggregates. These short protein sequences are called aggregation-prone regions (APRs) and consist of 5-15 amino acids [3,4]. APR-mediated protein aggregation is a highly specific self-association process $[2,5]$.

Importantly, APRs have been shown to be necessary and sufficient for protein aggregation. As most proteins harbor APR segments within their primary structure and because aggregation is sequence specific, it is possible to induce aggregation and subsequently functional depletion of a protein by exposing it to a short target-specific aggregating peptide. The interaction of these APRs depends highly on the sequences and shows a predisposition toward self-association to form intermolecular $\beta$-sheets [6]. The presence of APRs within a target peptide sequence can be identified by prediction algorithms, such as TANGO [7].

As most of the Arabidopsis and maize proteins harbor aggregation-prone sequence segments within their primary structure, we demonstrated that functional depletion of a protein can be induced by exposing it to a specific APR [1]. Overexpression of different APRs, derived from a single protein or protein family, fused to a fluorescent carrier, results in specific knockdowns similar, albeit often less strong, to previously described genetic mutants. Surprisingly, protein aggregates are not cytotoxic in plants and the synthetic APRs can be targeted also to different cellular compartments or be secreted in the apoplast, allowing highly selective protein knockouts to be obtained. In addition, the intrinsic nature of APRs to form $\beta$-sheet structures assures their structural stability when overexpressed in cells. Hence, the APR expression approach can be used as an innovative knockdown method to inactivate proteins by specific in vivo "pull-down" in defined subcellular compartments of maize.

This chapter describes how to select APR peptides for subsequent overexpression in maize to obtain a specific protein knockdown by means of the Pi technology (Fig. 1). An initial scrupulous experimental design is crucial to achieve positive results and several criteria must be followed. The first step is to run the target protein peptide sequence through the TANGO algorithm to predict aggregation-nucleating sequences in target proteins [7]. More than $80 \%$ of the Arabidopsis proteome contains APRs and, in our experience, similar results can also be expected for the maize proteome [3]. Ideally, the target protein is encoded by a single gene, although also protein families bearing the same APR sequence may be successfully targeted [1]. The APR sequences are selected as the peptide sequences with the highest probability to cross-aggregate by forming intermolecular $\beta$-strands. In the TANGO output, this probability is represented as the percentage 


\section{Target protein}

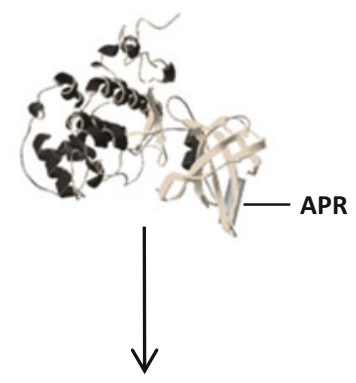

\section{APR selection}

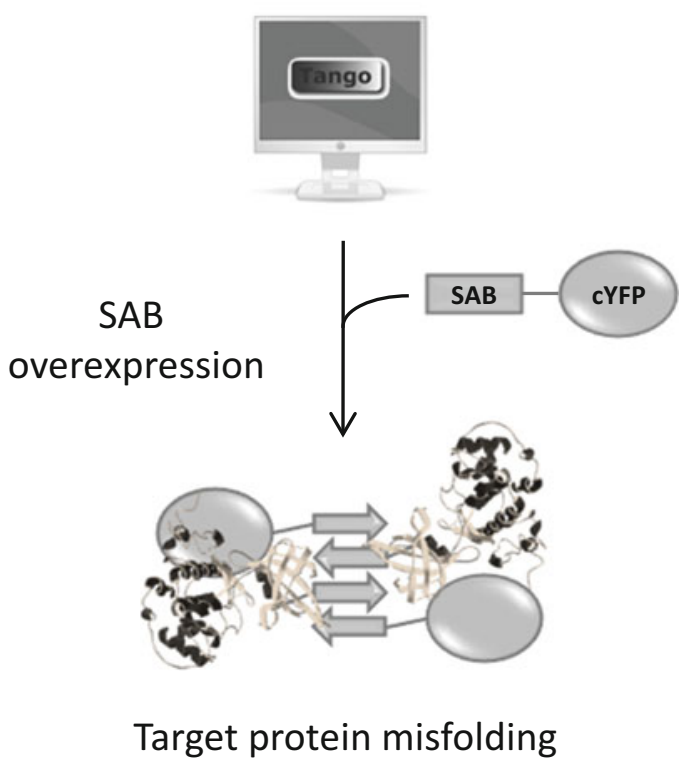

Fig. 1 Protein interference technology working scheme. The target protein primary sequence is processed via TANGO algorithm. Aggregation prone regions (APRs) are selected and engineered in synthetic aggregating blocks (SABs), fused to citrine yellow fluorescent protein (cYFP) carrier. SAB-cYFP stable overexpression in maize leads to the target protein misfolding and functional inactivation

in the $\beta$-aggregation propensity calculation. We restricted the in planta analyses to APRs with $\beta$-aggregation propensity score above $50 \%$, but lower threshold could also be explored. To ensure the use of APRs that are unique for the target protein, a basic local alignment search tool, BLAST ${ }^{\circledR}$, (https://blast.ncbi.nlm.nih.gov/Blast. cgi), is used to compare the APR sequence to all possible fragments of the same size in the maize proteome, provided the word-size is set to be sufficiently small for peptide matching (e.g., [3]). 
Table 1

Nucleotide and peptide sequences for pEN-L1-SAB-L2

\begin{tabular}{|c|c|c|}
\hline & Nucleotide sequence & Peptide sequence \\
\hline attLl & $\begin{array}{l}\text { CAAATAATGATTTTATTTTGACTGATAGTG } \\
\text { ACCTGTTCGTTGCAACACATTGATGAGCAATGCTTT } \\
\text { TTTATAATGCCAACTTTGTACAAAAAAG } \\
\text { CAGGCTTA }\end{array}$ & $\mathrm{N} / \mathrm{A}$ \\
\hline attL2 & $\begin{array}{l}\text { TACCCAGCTTTCTTGTACAAAGTTGGCATTA } \\
\text { TAAGAAAGCATTGCTTATCAATTTGTTGCAACGAACA } \\
\text { GGTCACTATCAGTCAAAATAAAATC } \\
\text { ATTATTTG }\end{array}$ & $\mathrm{N} / \mathrm{A}$ \\
\hline Linker & $\begin{array}{l}\text { GCCGGCAGCCCGAAGGGCGCCCCGGCCGCCA } \\
\text { AGGGCAGCGGCGCC }\end{array}$ & AGSPKGAPAAKGSGA \\
\hline N-ter FR & GAGAACGCCGTGGAC & ENAVD \\
\hline C-ter FR & GGCACCCCGACCAGGGAGGAG & GTPTREE \\
\hline
\end{tabular}

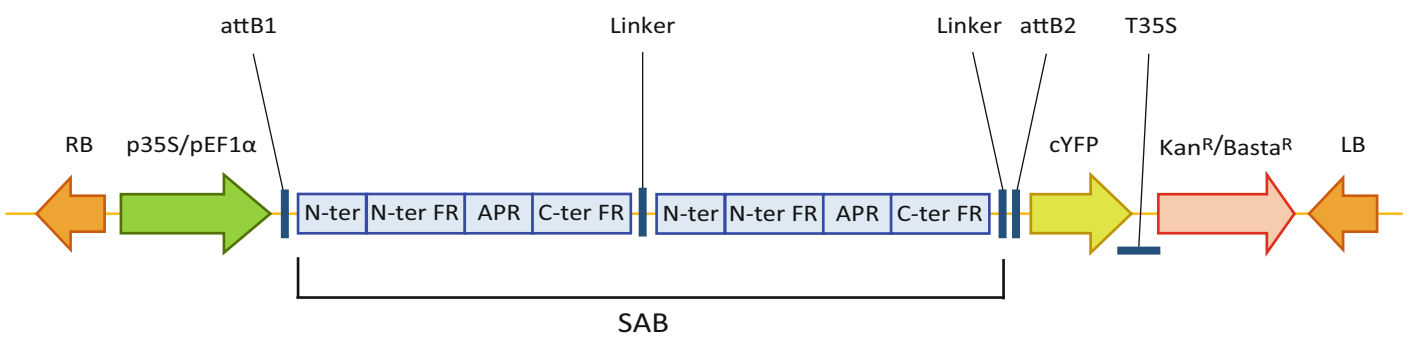

Fig. 2 Schematic representation of constructs expressing different APR variants, indicated as synthetic aggregating blocks (SABs). SABs are fused to cYFP at their C-terminus. $p 35 S$ CaMV 35S promoter, $p E F 1 \alpha$ elongation factor promoter, $\mathrm{N}$-ter first $6 \mathrm{AA}$ of the target protein $\mathrm{N}$-terminus, $A P R$ aggregation prone region, $\mathrm{N}$ ter FR APR N-terminal flanking region, $C$-ter FR APR C-terminus flanking region, cYFP citrine yellow fluorescent protein, $\operatorname{Kan}^{R} /$ Basta $^{R}$ kanamycin/Basta resistance gene, $R B$ right border, $L B$ left border

Once candidate APRs that are unique for the target protein are selected, their sequence is further optimized by addition of charged flanking regions (FRs) and linkers to obtain synthetic aggregating blocks (SABs) (Table 1). FRs are composed of five to seven charged residues inserted at the $\mathrm{N}$-terminal and $\mathrm{C}$-terminal flanks of the APRs to slow down aggregation and, thus, limit the formation of insoluble aggregates, working as natural "aggregation gatekeepers" [8]. APRs and FRs are cloned in tandem repeats, separated by a linker sequence, to amplify their aggregation potential and are preceded at their $5^{\prime}$ prime by the sequence coding for the first 6 amino acids of the target protein (Fig. 2 and Table 1). Each SAB is also Cterminally attached to a citrine yellow fluorescent protein (cYFP) for 
visualization, solubility increase, and biochemical detection. Additionally, it is also possible to express APRs in specific subcellular compartments by fusing a targeting sequence of choice either $\mathrm{N}$ terminally to SABs (for instance, for chloroplast targeting) or Cterminally to cYFP. SABs are finally cloned in Gateway ${ }^{\circledR}$ expression vectors for Nicotiana benthamiana and maize transformation and fused to overexpression or tissue-specific promoters [1].

The next step is the evaluation of APR-induced aggregate formation in a transient expression system, i.e., by Agrobacterium tumefaciens transformation and infiltration in young N. benthamiana leaves. Agrobacterium-mediated transient expression is a convenient, fast, and reproducible tool to produce recombinant proteins in approximately 6 days from the bacterial inoculation. This procedure allows confirming, with biochemical assays, the ability of the selected APRs to aggregate. In addition, APR expression, subcellular localization, and tendency to induce aggregates may also be evaluated by confocal laser scanning microscope (CLSM) imaging.

The aggregate formation is biochemically assessed by total protein extraction from $N$. benthamiana under native conditions 3 days after infiltration, followed by Blue Native Polyacrylamide gel electrophoresis (BN-PAGE) and Western blotting with anti-green fluorescent protein (GFP) antibodies. This assay confirms the presence of APR-induced high-molecular weight complexes, indicating that soluble aggregates are formed and will likely target the desired protein of interest.

In BN-PAGE, proteins remain in their native state and, therefore, separate on the basis of their charge-to-mass ratio. Although this technique does not provide direct measurements of the molecular weight, it can be useful to acquire information, such as protein charge or subunit composition, i.e., aggregates formation. Only APRs coded by constructs that induce the formation of complexes with a molecular mass of more than $55-60 \mathrm{kDa}$ (such as the SABYFP monomeric form) are selected for subsequent transformation into maize.

The protocol accurately describes the biomolecular procedures required to reach this selection step. Lastly, immature embryos of the maize B104 inbred line [9] are co-cultivated with the A. tumefaciens strain EHA101 engineered with the pBb7m34GW expression vectors containing the selected APRs [10]. The derived T0 transgenic maize plants, expressing the APRs at the correct localization, are selected and propagated, ideally until the homozygous state, by routine procedures. The resulting transgenic lines are then analyzed for the appearance of phenotypes compatible with the desired target protein knockdown. 


\section{Materials}

2.1 Plant Material

2.2 Strains and Competent Cells

\subsection{Vectors for}

Multisite Gateway ${ }^{\mathbb{R}}$ Cloning

\subsection{Media}

2.5 Solutions, Reagents, and Buffers
Nicotiana benthamiana plants approximately 4-5 weeks old.

1. Agrobacterium tumefaciens C58 strain.

2. A. tumefaciens C58 strain containing the pBin61-P19 vector [11].

3. A. tumefaciens EHAl01 strain for maize transformation.

4. A. tumefaciens C58 electro-competent cells.

5. Escherichia coli $\mathrm{DH} 5 \alpha$ heat shock-competent cells.

6. EHAl01 heat shock-competent cells.

1. Entry vectors at a concentration of approximately $30-50 \mathrm{ng} / \mu$ $\mathrm{L}$ : pEN-L4-2-Rl, containing the cauliflower mosaic virus 35 (CaMV 35S) promoter [12] for overexpression in $N$. benthamiana; pEN-L4-EFl $\alpha$-Rl containing the Elongation Factor $(\mathrm{EFl} \alpha)$ promoter for overexpression in maize (see Note 1) [10]; pEN-L1-SAB-L2 vector (custom-made plasmid delivered as a pUC57 vector, see Subheading 3.1); pEN-R2cYFP-L3 to generate translational fusions with cYFP (kind gift of Hilde Nelissen, VIB-Gent University).

2. Destination vectors at a concentration of approximately 100-150 ng/mL: pK7m34GW for overexpression in $N$. benthamiana and $\mathrm{pBb} 7 \mathrm{~m} 34 \mathrm{GW}$ for maize transformation [12], conferring in planta resistance to kanamycin and phosphinothricin (BASTA) respectively; these vectors also contain the selectable marker cassette for spectinomycin resistance in bacteria.

3. Gateway ${ }^{\circledR}$ LR Clonase ${ }^{\mathrm{TM}}$ II Plus enzyme mix (Invitrogen).

1. LB medium: $10 \mathrm{~g} / \mathrm{L}$ tryptone, $5 \mathrm{~g} / \mathrm{L}$ yeast extract, $5 \mathrm{~g} / \mathrm{L}$ $\mathrm{NaCl}, \mathrm{pH} 7.0$, autoclave.

2. Solid LB medium: LB medium supplemented with $15 \mathrm{~g} / \mathrm{L}$ agar, autoclave.

3. YEB medium: $5 \mathrm{~g} / \mathrm{L}$ bacto beef extract, $1 \mathrm{~g} / \mathrm{L}$ bacto yeast extract, $5 \mathrm{~g} / \mathrm{L}$ peptone, $\mathrm{pH} 7.2$, autoclave.

4. Solid YEB medium: YEB medium supplemented with $15 \mathrm{~g} / \mathrm{L}$ agar, autoclave.

1. Antibiotics stock solutions: spectinomycin $100 \mathrm{mg} / \mathrm{mL}$, filter sterilize; gentamicin $20 \mathrm{mg} / \mathrm{mL}$, filter sterilize; rifampicin $50 \mathrm{mg} / \mathrm{mL}$ in dimethyl sulfoxide (DMSO); kanamycin $50 \mathrm{mg} / \mathrm{mL}$, filter sterilize; all solutions can be kept at $-20^{\circ} \mathrm{C}$ in $0.5 \mathrm{~mL}$ aliquots ( see Note 2 ). 
2. TE buffer: $1 \mathrm{mM}$ ethylenediaminetetraacetic acid (EDTA), $10 \mathrm{mM}$ tris(hydroxymethyl)aminomethane (Tris) $-\mathrm{HCl}, \mathrm{pH} 8.0$, autoclave.

3. Proteinase K solution.

4. Acetosyringone $\left(3^{\prime}, 5^{\prime}\right.$-dimethoxy-4'-hydroxyacetophenone $)$ : $0.1 \mathrm{M}$ in DMSO, store at $+4{ }^{\circ} \mathrm{C}$.

5. 2-( $N$-morpholino)ethanesulfonic acid (MES) buffer: $0.5 \mathrm{M}$ ( $\mathrm{pH}$ 5.6), filter sterilize and store at $+4{ }^{\circ} \mathrm{C}$ (see Note 3$)$.

6. $\mathrm{MgCl}_{2}: 1 \mathrm{M}$, autoclave.

7. Infiltration buffer: $10 \mathrm{mM} \mathrm{MgCl} 2,10 \mathrm{mM}$ MES (pH 5.6), $0.1 \mathrm{mM}$ acetosyringone.

8. Protein native extraction buffer (NEB): $20 \mathrm{mM}$ Tris- $\mathrm{HCl}$ ( $\mathrm{pH} 7.5), 150 \mathrm{mM} \mathrm{NaCl}, 18 \mathrm{mM}$ 3-[(3-Cholamidopropyl) dimethylammonio]-1-propanesulfonate hydrate (CHAPS), cOmplete ${ }^{\mathrm{TM}}$ ULTRA tablets ( 1 tablet for $10 \mathrm{~mL}$ solution).

9. Semi-dry blotting buffer: $12 \mathrm{mM}$ Tris, $96 \mathrm{mM}$ glycine, $20 \%$ (v/ v) methanol, $0.05 \%(\mathrm{v} / \mathrm{v})$ sodium dodecyl sulfate (SDS), store at $+4{ }^{\circ} \mathrm{C}$.

10. Phosphate-buffered saline (PBS) buffer: $137 \mathrm{mM} \mathrm{NaCl}, 2.7 \mathrm{mM}$ $\mathrm{KCl}, 10 \mathrm{mM} \mathrm{Na}_{2} \mathrm{HPO}_{4}, 1.8 \mathrm{mM} \mathrm{KH}_{2} \mathrm{PO}_{4}, \mathrm{pH} 7.4$, autoclave.

11. Washing buffer (PBS-T): $0.1 \% \quad(\mathrm{v} / \mathrm{v})$ polysorbate20 (Tween 20) in PBS.

12. Blocking buffer: PBS-T supplemented with $3 \%(\mathrm{v} / \mathrm{v})$ skimmed milk.

13. Acetic acid: $8 \%(\mathrm{v} / \mathrm{v})$.

14. Anti-GFP monoclonal antibody (mouse) horseradish peroxidase (HRP) conjugated (anti-GFP-HRP) (Miltenyi Biotec).

2.6 Kits, Gels, and Membranes
1. QIAprep Spin Miniprep Kit plasmid purification kit.

2. Quick Start ${ }^{\mathrm{TM}}$ Bradford $1 \times$ Dye Reagent.

3. NativePAGETM ${ }^{\text {TM }}{ }^{\circledR}{ }^{\circledR} 3-12 \%$ Bis-Tris Gels $1.0 \mathrm{~mm}$, 10 well (Invitrogen).

4. NativePAGE ${ }^{\mathrm{TM}}$ 5\% G-250 Sample Additive (Invitrogen).

5. NativePAGETM running buffer kit (Invitrogen).

6. NativeMark ${ }^{\mathrm{TM}}$ unstained protein standard (Invitrogen).

7. Immobilon-P polyvinylidene fluoride (PVDF) membrane: $0.45 \mu \mathrm{m}$.

8. Whatman ${ }^{\mathrm{TM}} 3 \mathrm{MM}$ blotting paper.

9. Western Lightning ${ }^{\circledR}$ Plus-Enhanced Chemiluminescence (ECL) substrate.

10. Hyperfilm ECL.

11. $3 \mathrm{M}^{\mathrm{TM}}$ Micropore ${ }^{\mathrm{TM}}$ surgical tape. 
2.7 Equipment

2.8 Databases and Software
1. Mortars and pestles.

2. Small $(8 \mathrm{~cm})$ and large $(13 \mathrm{~cm})$ pots.

3. Vermiculite.

4. Fertilizers: Osmocote ${ }^{\circledR}$ and Scotts ${ }^{\circledR}$.

5. Incubators and shakers at $28^{\circ} \mathrm{C}$ and $37^{\circ} \mathrm{C}$.

6. Orbital table-top shaker.

7. $1 \mathrm{~mL}$ syringes.

8. $1.5 \mathrm{~mL}$ microcentrifuge tubes, $50 \mathrm{~mL}$ Falcon tubes, $1.5 \mathrm{~mL}$ and $2 \mathrm{~mL}$ Eppendorf tubes.

9. Protective glasses.

10. Spectrophotometer.

11. Xcell SureLock ${ }^{\mathrm{TM}}$ Mini-Cell (Invitrogen) PAGE running system.

12. Semi-dry blotting apparatus.

13. Developing cassettes and film-developing apparatus with developer and fixer.

14. Computer (Windows or Machintosh) system for bioinformatics analyses, databases searches, and sequence analysis.

1. GDB database (http://www.maizegdb.org/).

2. PLAZA2.5 (http://bioinformatics.psb.ugent.be/plaza/vers ions/plaza_v2_5/) [13].

3. TANGO (http://www.switchlab.org/bioinformatics/tango) [7].

4. BLASTp ${ }^{\circledR}$ (https://blast.ncbi.nlm.nih.gov/Blast.cgi).

\section{Methods}

\subsection{APRs In Silico Analysis}

1. Select the target protein of interest, preferentially encoded by a single gene ( see Note 4).

2. Download the peptide sequence of the desired target protein from the maize GDB database or PLAZA2.5 ( see Note 5).

3. Open TANGO and log in.

4. Select "calculation" in the toolbox, paste the target peptide sequence, and press "Calculate" (see Note 6).

5. Keep default parameters and conditions.

6. Select the short APR peptide sequences as the amino acids (AAs) with a cross $\beta$-aggregation propensity higher than $50 \%$ (see Note 7). 
7. Run the 5-10 AA APR sequences in BLASTp ${ }^{\circledR}$ with the nonredundant (nr) protein sequence database and Zea mays (taxid:4577) as organism.

8. Select only APRs that are unique for the target protein to knock down (see Notes 4 and 8 ).

9. Design the SABs for LR multisite Gateway ${ }^{\circledR}$ cloning in a sequence analysis software (such as Vector NTI ${ }^{\circledR}$, Invitrogen) as represented in Fig. 2. Insert the following synthetic sequences in this order: six AAs of the $\mathrm{N}$-terminus (N-ter) of the target protein; five AAs of $\mathrm{N}$-ter flanking region (N-ter FR); APR; seven AAs of the C-terminus (C-ter) FR; Linker; repeat the sequence, N-ter FR-APR-C-ter FR-Linker (see Fig. 2 and Table 1 for SAB schematic representation and sequences) (see Note 9).

10. Place an order for the $S A B$ sequences to a gene synthesis company, such as Genescript ${ }^{\circledR}$, after flanking them with the attLl and attL2 cloning sites, so they are ready-to-use for three fragment recombination multisite Gateway ${ }^{\circledR}$ cloning ( see Note 10).

11. Choose the SABs to be delivered in a cloning vector, such as a pUC57 plasmid, for direct use as entry vectors for LR recombination (pEN-L1-SAB-L2).

3.2 APRs Cloning in pK7m34GW and pBb7m34GW Expression Vectors
1. For the MultiSite Gateway ${ }^{\circledR}$ LR recombination reaction between multiple entry clones, in a $1.5 \mathrm{~mL}$ microcentrifuge tube, mix $6 \mu \mathrm{L}$ TE, $1 \mu \mathrm{L}$ pK7m34GW or pBb7m34GW (approximately $100-150 \mathrm{ng} / \mu \mathrm{L}$ ), $1 \mu \mathrm{L}$ pEN-L4-2-Rl or $1 \mu \mathrm{L}$ pEN-L4-EFl $\alpha$-Rl, $1 \mu \mathrm{L}$ pEN-L1-SAB-L2 and $1 \mu \mathrm{L}$ pEN-R2-cYFP-L3 (see Note 11) and keep at room temperature.

2. Briefly vortex the LR Clonase ${ }^{\mathrm{TM}}$ II Plus enzyme mix and keep it on ice.

3. Add $2 \mu \mathrm{L}$ of LR Clonase ${ }^{\mathrm{TM}}$ II Plus enzyme mix to the microcentrifuge tube (step $\mathbf{l}$ ) and gently mix.

4. Spin down and incubate the $\mathrm{LR}$ reaction at $25^{\circ} \mathrm{C}$ for $16 \mathrm{~h}$ (or overnight).

5. Add $1 \mu \mathrm{L}$ of $2 \mu \mathrm{g} / \mu \mathrm{L}$ Proteinase $\mathrm{K}$ solution to neutralize the clonase enzyme.

6. Gently mix and spin down briefly.

7. Incubate the reaction at $37^{\circ} \mathrm{C}$ for $10 \mathrm{~min}$, spin down, and place on ice.

8. Transform $2 \mu \mathrm{L}$ of the LR reaction mix into $50 \mu \mathrm{L}$ E. coli $\mathrm{DH} 5 \alpha$ heat shock-competent cells. 


\subsection{APRs \\ Biochemical \\ Assessment by \\ BN-PAGE and Western \\ Blotting}

3.3.1 Agrobacteriummediated Infiltration of p35S-SAB-cYFP Constructs
9. Spread $20 \mu \mathrm{L}$ and $100 \mu \mathrm{L}$ aliquots onto plates of solid LB medium containing $100 \mu \mathrm{g} / \mathrm{mL}$ spectinomycin.

10. Incubate the plates upside down overnight at $37^{\circ} \mathrm{C}$.

11. Select six single E. coli colonies and inoculate them in $10 \mathrm{~mL}$ of $\mathrm{LB}$ medium containing $100 \mu \mathrm{g} / \mathrm{mL}$ spectinomycin.

12. Incubate overnight at $37^{\circ} \mathrm{C}$ in a shaker at $220 \mathrm{rpm}$.

13. Isolate the expression vectors with the QIA miniprep kit, including all clean-up steps.

14. Elute the DNA with $50 \mu \mathrm{L}$ of sterile bi-distilled water.

15. Determine the DNA concentration with the spectrophotometer.

16. Sequence six isolated plasmids per construct.

17. After the sequence analysis confirmation, make glycerol stocks and transform one plasmid per construct into Agrobacterium C58 electrocompetent cells or EHAl01 heat shock-competent cells.

18. Plate the transformed bacteria onto $\mathrm{YEB}$ agar plates containing $20 \mu \mathrm{g} / \mathrm{mL}$ gentamycin, $100 \mu \mathrm{g} / \mathrm{mL}$ spectinomycin, and $25 \mu \mathrm{g} / \mathrm{mL}$ rifampicin for C58 Agrobacterium strain, or onto YEB agar plates containing $100 \mu \mathrm{g} / \mathrm{mL}$ spectinomycin and $25 \mu \mathrm{g} / \mathrm{mL}$ kanamycin for the EHAl01 Agrobacterium strain.

19. Incubate upside down at $28{ }^{\circ} \mathrm{C}$ for $2-3$ days (in the dark for plates containing rifampicin).

20. Pick single colonies, streak them on selective YEB agar, and make glycerol stocks (see Notes 12 and 13).

1. Sow approximately $20-30 \mathrm{~N}$. benthamiana seeds in a small pot containing wet soil and transfer for germination in a greenhouse under controlled growth conditions at $21{ }^{\circ} \mathrm{C}$ and $65 \%$ humidity.

2. After 2 weeks, transfer seedlings in single, large pots containing soil and vermiculite in a 3:1 ratio mixed with a teaspoon full of Osmocote ${ }^{\circledR}$ fertilizer.

3. Water and keep at $21{ }^{\circ} \mathrm{C}$ and $65 \%$ humidity under controlled growth conditions.

4. Fertilize after 2 weeks with $1 \mathrm{~g} / \mathrm{L}$ Scotts fertilizer 20:20:20.

5. Inoculate Agrobacterium strains transformed with the p35SSAB-cYFP constructs, in $10 \mathrm{~mL}$ YEB supplemented with $20 \mu \mathrm{g} / \mathrm{mL}$ gentamycin, $100 \mu \mathrm{g} / \mathrm{mL}$ spectinomycin, $10 \mathrm{mM}$ MES ( $\mathrm{pH} 5.6$ ), and $20 \mu \mathrm{M}$ acetosyringone, in 50-mLFalcon ${ }^{\circledR}$ tubes leaving the cap half open and sealed with $3 \mathrm{M}^{\mathrm{TM}}$ Micropore $^{\mathrm{TM}}$ surgical tape (see Note 2 ). 
6. In parallel, inoculate Agrobacterium containing the pBin6lP19 vector in $10 \mathrm{~mL}$ YEB added with $20 \mu \mathrm{g} / \mathrm{mL}$ gentamycin, $50 \mu \mathrm{g} / \mathrm{mL}$ kanamycim, $10 \mathrm{mM}$ MES ( $\mathrm{pH} 5.6$ ), and $20 \mu \mathrm{M}$ acetosyringone ( see Note 2 ). Coexpression of p19 protein from tomato bushy stunt virus is used for suppression of transgene silencing resulting in increased expression of the desired proteins [11].

7. Incubate the cultures at $28^{\circ} \mathrm{C}$ for 2 days.

8. To measure and record the optical density at $600 \mathrm{~nm}\left(\mathrm{OD}_{600}\right)$ of the cultures, make a 1:5 dilution of each culture and place $1 \mathrm{~mL}$ of the diluted cultures into a plastic cuvette. Read the OD with the spectrophotometer. Make blank controls with YEB medium and appropriate antibiotics.

9. Calculate the amount of each culture needed to have a final $\mathrm{OD}_{600}$ of 1.5 in a final volume of $2 \mathrm{~mL}$ (see Note 14).

10. Transfer the bacterial cultures in $2 \mathrm{~mL}$ Eppendorf tubes and spin down the appropriate volumes by centrifugation at $4000 \times g$ for $20 \mathrm{~min}$.

11. Discard the supernatant.

12. Resuspend the pellets obtained in step $\mathbf{1 0}$ in $2 \mathrm{~mL}$ infiltration buffer by vigorous flicking ( see Note 3 ).

13. Incubate at room temperature for $2-3 \mathrm{~h}$ to let the acetosyringone activate the Agrobacterium virulence genes.

14. After incubation, mix the Agrobacterium cultures $1: 1$ and make a $1 \mathrm{~mL}$ infiltration mix (see Note 15).

15. Prepare to infiltrate the bacterial mix into the abaxial side of approximately 4 -week-old $N$. benthamiana leaves with a $1 \mathrm{~mL}$ syringe without needle. Make a small incision in the epidermis on the leaf abaxial side by a soft touch with a hypodermic needle.

16. To infiltrate the Agrobacterium cell mixture, simply press the syringe on the leaf at the incision level and exert a counterpressure with your finger tip on the other side (see Note 16).

17. Highlight the perimeter of the injected area that will turn dark green with a permanent marker on the upper side of the leaf.

18. Continue to inject until the infiltration mixture will stop to expand.

19. Repeat the procedure until the entire leaf is infiltrated.

20. Transfer the plants under controlled growth conditions at $21{ }^{\circ} \mathrm{C}$ and $65 \%$ humidity and water them.

21. Three days after infiltration, collect the injected leaf material, flash freeze in liquid nitrogen, and store at $-70{ }^{\circ} \mathrm{C}$ for subsequent biochemical analyses (see Note 17). 
3.3.2 BN-PAGE
1. Grind the leaf material obtained in Subheading 3.3.1 in icecold mortars to a fine powder.

2. Fill an ice-cold $2 \mathrm{~mL}$ Eppendorf tube containing $500 \mu \mathrm{L} \mathrm{NEB}$ with the ground material.

3 . Vortex and place on ice.

4. Incubate approximately $15-20 \mathrm{~min}$ on ice and after $10 \mathrm{~min}$ mix thoroughly by inverting the tubes.

5. Centrifuge at $14,000 \times g$ for $20 \mathrm{~min}$ at $4{ }^{\circ} \mathrm{C}$ to pellet the cell debris.

6. Collect the supernatant in a new ice-cold $1.5 \mathrm{~mL}$ Eppendorf tube and keep on ice. If leaf particulate is still present in the supernatant, repeat centrifugation in step 5 for $10 \mathrm{~min}($ see Note 18 ).

7. To measure protein concentration, perform a Bradford assay [14] by preparing an appropriate number of cuvettes containing $990 \mu \mathrm{L}$ of Quick Start ${ }^{\text {TM }}$ Bradford $1 \times$ Dye Reagent $($ see Note 19).

8. Add to the cuvette $10 \mu \mathrm{L}$ of protein extracts obtained in step 6 , diluted 1:10 in NEB and add $10 \mu \mathrm{L}$ of NEB in the blank control.

9. Mix thoroughly and incubate $15 \mathrm{~min}$ on the work-bench.

10. After incubation, record the OD at $595 \mathrm{~nm}\left(\mathrm{OD}_{595}\right)$, after putting the blank control at a null value.

11. Calculate the protein concentrations by using the calibration curve extrapolated from bovine serum albumin (BSA) $\mathrm{OD}_{595}$ reads.

12. For the BN-PAGE electrophoresis, prepare $1.5 \mathrm{~mL}$ Eppendorf tubes containing the samples obtained in step 6 diluted in $\mathrm{NEB}$ to have $60 \mu \mathrm{g}$ of total proteins in a $25 \mu \mathrm{L}$ volume.

13. Add $10 \%(\mathrm{v} / \mathrm{v})$ glycerol and $2 \mu \mathrm{L}$ NativePAGETM Coomassie G-250 Sample Additive to each sample (see Note 20).

14. Wash the wells of a $3-12 \%$ Novex ${ }^{\circledR}$ Bis-Tris gradient gel with NativePAGETM cathode buffer twice prior to assembling into the BN-PAGE X-cell Sure-lock ${ }^{\mathrm{TM}}$ running apparatus (see Note $20)$.

15. Prepare the Xcell SureLock ${ }^{\mathrm{TM}}$ Mini-Cell running apparatus: mount the gels, fill the inner chamber with $200 \mathrm{~mL}$ NativePAGETM $^{\text {TM }}$ cathode buffer $\left(10 \mathrm{~mL}\right.$ NativePAGE ${ }^{\text {TM }} 20 \times$ running buffer, $1 \mathrm{~mL}$ NativePAGETM $20 \times$ cathode buffer additive in sterile water) and the outer chamber with $400 \mathrm{~mL}$ NativePAGETM anode buffer obtained by diluting $20 \times$ NativePAGE ${ }^{\text {TM }}$ running buffer. 
16. Load the samples prepared in step 12 into a gradient NativePAGE $^{\text {TM }}$ Novex $^{\circledR}$ 3-12\% Bis-Tris gel.

17. Use $10 \mu \mathrm{L}$ of NativeMark ${ }^{\mathrm{TM}}$ unstained protein standard as a marker, added with $10 \%(\mathrm{v} / \mathrm{v})$ glycerol and $2 \mu \mathrm{L}$ of NativePAGE 5\% G-250 sample additive.

18. Perform the electrophoresis at room temperature for $2 \mathrm{~h}$ at 120V ( see Note 21).

\subsubsection{Western Blotting}

1. Activate a PVDF membrane, previously cut to the same size of the gel, by incubation in $100 \%(\mathrm{v} / \mathrm{v})$ methanol for $15 \mathrm{~s}$.

2. Equilibrate the membrane in semi-dry blotting buffer for 5 min.

3. Soak five Whatman ${ }^{\mathrm{TM}}$ filter papers, previously cut to the same size of the gel, and the PVDF membrane in semi-dry blotting buffer.

4. Transfer the proteins in the gel from Subheading 3.3.2 onto a PVDF membrane by semi-dry blotting.

5. After the run, carefully dismantle the gel from the plastic cast and place it in a semi-dry blotting apparatus with material in step $\mathbf{l}$ in this order: from anode to cathode, two Whatman ${ }^{\mathrm{TM}}$ filter papers, PVDF membrane, native gel, and three Whatman $^{\text {TM }}$ filter papers.

6. Perform the blot at a fixed current of $45 \mathrm{~mA}$ for $1.15 \mathrm{~h}$ (see Note 22).

7. Fix proteins on the PVDF membrane in $8 \%(\mathrm{v} / \mathrm{v})$ acetic acid for $20 \mathrm{~min}$ on a table-top shaker.

8. Air-dry the membrane.

9. Destain the Coomassie blue from the PVDF membrane with $100 \%(\mathrm{v} / \mathrm{v})$ methanol and wash twice in PBS buffer to remove the methanol residues.

10. Block the proteins on the membrane by incubation in blocking buffer overnight at $4{ }^{\circ} \mathrm{C}$ or for $\mathrm{l} \mathrm{h}$ at room temperature (see Note 23).

11. Discard the blocking solution and add $10 \mathrm{~mL}$ of blocking solution containing 1:5000 anti-GFP-HRP monoclonal antibody for immunodetection of the SAB-cYFP aggregates (see Note 16).

12. Incubate the membrane for $\mathrm{l}$ h at room temperature.

13. Discard the antibody solution (see Note 24) and wash the membrane with PBS-T buffer for $15 \mathrm{~min}$.

14. Discard the solution and wash two times with PBS-T for $5 \mathrm{~min}$.

15. Gently dry the membrane for $2 \mathrm{~s}$ with adsorbent paper to remove excess of wash solution. 
16. To develop the membrane with an ECL kit, mix equal amounts of enhanced luminol reagent and oxidizing reagent (usually $1 \mathrm{~mL}$ of each substrate is sufficient) and incubate for $1 \mathrm{~min}$ at room temperature.

17. Gently dry the membrane with adsorbent paper for $2 \mathrm{~s}$ and place it in a developing cassette between transparent plastic foils.

18. In a dark room, place a Hyperfilm ECL on the top of the membrane with firm hands.

19. Detect the chemiluminescence emitted from the filter after 5 min by using a film developer apparatus.

20. Repeat the procedure at different times, usually between 5 and 60 min depending on the cYFP signal intensity.

21. Analyze the results and select the APRs that induce high molecular-weight aggregates, when expressed in the $35 \mathrm{~S}$ SAB-YFP constructs, for subsequent maize transformation ( see Note 25).

4 Notes

1. To drive transgene overexpression in maize, better results are obtained when the elongation factor promoter $(\mathrm{pEFl} \alpha)$ from Brachypodium distachyon is used instead of the p35S from CaMV [10]. When a mesophyll-specific expression is desired, a phosphoenol pyruvate carboxylase (PEPC) promoter can be successfully used [1].

2. Rifampicin is a light-sensitive antibiotic that degrades fairly quickly in the presence of light and, in solution, it loses its activity. Therefore, because shakers in most laboratories are kept under light conditions, we recommend avoiding addition of this antibiotic to the YEB medium. The Agrobacterium strain transformed with the pBIN61-P19 vector is resistant to rifampicin, gentamycin, and kanamycin, but, for the abovementioned reasons, only the last two are used for inoculation in liquid YEB medium. Moreover, when preparing the medium for P19 cultures, consider an amount that will be sufficient to be injected together with each p35S-SAB-cYFP Agrobacterium-expressing construct. Finally, in the experiment, always include also a negative culture control (medium with antibiotics) to make sure to avoid any medium contamination.

3. The $\mathrm{pH}$ of the MES solution can be unstable. If the solution is not freshly prepared, always control that the $\mathrm{pH}$ is in the 5.6-5.7 range before use. Filter sterilization is advised, because after autoclaving the solution can turn yellowish and, although 
the $\mathrm{pH}$ does not change measurably, the nature of the byproducts is unknown.

4. This approach could be applied also to knock down protein families, when predicted aggregation-prone peptides would overlap across all family members [1]. To be able to evaluate the results in the optimal way possible, it would be ideal to knock down a protein family of which the knockdown would lead to known, or easy-to score, phenotypes.

5. The PLAZA2.5 bioinformatics platform is ideal when searching for maize protein sequences orthologous to others from different crop or model plant species [13].

6 . In the calculation output, it is represented in the " $\beta$ aggregation propensity" column.

7. The TANGO algorithm available online is suitable only to process proteins with a sequence of up to 500 amino acids. When longer sequences need to be analyzed, please contact the SWITCH laboratory (VIB-KU Leuven, Belgium).

8. Our results show that APRs with similar TANGO scores $(\geq$ $50 \%)$ and one mismatch, i.e., a sequence identity around $90 \%$, can bind the target proteins, whereas APRs with a TANGO score $\leq 50 \%$, but bearing two mismatches, i.e., less than $80 \%$ sequence identity, do not interact. Therefore, it is advised to select APRs with a TANGO score $>50 \%$ and unique for the target protein, unless a downregulation of an entire protein family sharing a similar APR sequence is desired [1].

9. Nucleotide sequences must be optimized for expression in maize.

10. Before placing the order for the $S A B$ sequences, make sure that the attL1 e attL2 recombination sequences for the three fragment multisite Gateway ${ }^{\circledR}$ cloning are correct. In fact, we noticed that when the Gateway ${ }^{\circledR}$ entry clones are recombined in silico, the attLl and attL2 nucleotide sequences contain one or two nucleotides that are not considered recombination sequences by the software, and/or are not listed in the manual. When these nucleotides are missed in the synthetic sequences, it will obviously lead to incorrect translation of the APRs due to a frameshift. Therefore, we advise to include as attLl and attL2 sequences all the nucleotides inserted after the in silico recombination between the $3^{\prime}$ end of the promoter sequence and the $5^{\prime}$ of the $\mathrm{SAB}$. As the $\mathrm{SAB}$ sequences are highly hydrophobic and, hence, problematic to synthesize, it is recommended to use a well-known and skilled gene synthesis company, such as Genscript ${ }^{\circledR}$. After the delivery of the order, follow the instructions provided with the supplied plasmids to dissolve the DNA at a working concentration of usually $200 \mathrm{ng} / \mu \mathrm{L}$. 
11. The concentrations of all entry vectors used are at approximately 30-50 ng/ $\mu \mathrm{L}$.

12. It is possible to further confirm the Agrobacterium clones by colony PCR or miniprep followed by sequencing, although, in our experience, these steps can be quite troublesome to carry out on Agrobacterium due to the thick cell walls. For this reason, the initial steps of the cell lysis must be extended and improved in both the cases.

13. Recombinant C58 Agrobacterium containing the p35S-SABcYFP in pK7m34GW expression vectors will be used for Agrobacterium-mediated infiltration experiments. Recombinant EHA101 Agrobacterium expressing pBb7m34GW vectors containing APRs selected at the end of Subheading 3.3.3, fused to cYFP and under the pEFl $\alpha$ promoter (or tissuespecific promoters), will be further inserted into immature B104 maize embryos.

14. For injecting two strains, one containing p35S-SAB-cYFP and one the pBin61-P19 vectors, each strain should be at $\mathrm{OD}_{600}$ of 0.75. It is important that all constructs have the same $\mathrm{OD}_{600} \pm 0.05$.

15. Prepare at least $6 \mathrm{~mL}$ of infiltration mix when injecting leaves for subsequent biochemical assays. To have enough leaf material for protein extraction, at least one entire leaf per construct combination is necessary; $3 \mathrm{~mL}$ infiltration mix should suffice for one leaf injection. We recommend injecting two leaves from different plants with each construct combination to avoid possible differences in expression levels after in planta transformation.

16. When punching the leaves, caution should be taken not to perforate the leaf through both sides; otherwise, the Agrobacterium mixture will not infiltrate into the intercellular space, but would just pass through the wound to the other leaf side. When multiple constructs are injected at the same time, be extra careful to not cross-contaminate the samples. Gloves should be changed after each construct combination injection and protective glasses must be worn during all the steps.

17. Although it is not strictly required to carry out the Pi technology main procedures, at this stage, it is also possible to check the APR expression by cYFP CLSM imaging. Although YFP is clearly visible by imaging with GFP settings, for visualization under the best conditions, it is advised to adjust the confocal microscope settings as much as, and whenever, possible for the YFP excitation (peak at $514 \mathrm{~nm}$ ) and emission spectra (peak at $527 \mathrm{~nm}$ ). To this aim, the best results, especially when imaging maize leaves, can be obtained by using a confocal microscope with adjustable BP and LP filters (such as the Olympus ${ }^{\circledR}$ 
FluoView ${ }^{\mathrm{TM}}$ FVl000 inverted confocal microscope). Importantly, cYFP is also the best fluorescent probe for maize CLSM imaging in our hands. As YFP protein only carries three amino acid differences with GFP, its use does not affect the extraordinary number of possibilities to perform biochemical analyses by means of commercial anti-GFP antibodies, beads for immunoprecipitation, etc.

18. Flash-frozen tissues can be stored for a long time at $-70{ }^{\circ} \mathrm{C}$ before protein extraction. However, once total proteins are isolated under native conditions, they need to be processed immediately by BN-PAGE to avoid unwanted denaturation and/or degradation of the protein aggregates contained in the extracts. To this end, samples must be kept also on ice during the whole procedure. The BN-PAGE technique may be also applied to maize leaf material by following the same procedure as described here.

19. Samples must be read in triplicates and a calibration curve with $0-1000 \mu \mathrm{g} / \mathrm{mL}$ BSA must be done in parallel.

20. In the procedure described here, a NativePAGETM NOVEX Bis-Tris Gel System (Invitrogen) is used. The NativePAGETM procedure is based on the use of Coomassie Brilliant Blue G250 in the sample buffer (sample additive), because it binds to proteins, conferring them a negative charge without denaturation. Moreover, Tricine (negatively charged) and Bis Tris (positively charged) salts are used as electrophoresis ions, allowing the electrophoresis procedure to proceed at nearly neutral pH (7.5-7.7). As the cathode buffer contains Coomassie blue, it has a deep blue color making gel loading very tricky. Therefore, to get a visual help during loading, it is advised to mark the wells in the precast gels with a black marker before starting the Xcell SureLock ${ }^{\mathrm{TM}}$ running cassette assembly. Due to the delicate nature of the $3-12 \%$ gradient native gels, it is also recommended to use always commercial precast gels together with reagents from the same company to avoid unwanted running problems due to unequal ions distribution, which are very common when gradient gels are cast in the laboratory.

21. Occasionally, the run may stop due to low current. In that case, set the voltage to $180 \mathrm{~V}$ for $40 \mathrm{~min}$.

22. Always perform the semi-dry blotting at a low current; otherwise, the native gel could melt.

23. This step, as well as steps $5-7$, is performed on an orbital tabletop shaker.

24. The YFP fluorescent protein is recognized by a great variety of commercial polyclonal and monoclonal anti-GFP antibodies, because it has a primary, secondary, and tertiary structure 
extremely similar to that of GFP. We advise to use the anti-GFP HRP-conjugated monoclonal antibody, because it is very specific and also allows the secondary antibody incubation step to be skipped during the immunoblotting experimental procedures. After use, the antibody solution can be kept at $-20^{\circ} \mathrm{C}$ and reused several times (tested up to four times).

25. After blotting, YFP-labeled aggregates may appear either as definite bands or as smears, at least twice the size of the APRYFP monomeric form (approximately $55-60 \mathrm{kDa}$ ). The smears indicate that differently sized aggregates are formed. In our experience, APRs inducing these kinds of aggregates are as efficient as those that induce only aggregates of one kind in achieving the target protein knockdown. Lastly, when an antibody against the target protein is available, we propose to perform a co-immunoprecipitation procedure, after coexpression of the target protein and the selected APRs in N. benthamiana, to confirm that the APRs of choice interact with the target protein of interest. This will strongly support a positive outcome of the Pi knockdown approach.

\section{Acknowledgments}

This work was supported by grants from the Agency for Innovation by Science and Technology ("Strategisch Basisonderzoek" project no. 60839), Ghent University ("Industrieel Onderzoeksfonds" F2011/IOF-Advanced121 and F2014/IOF-StarTT261 and Multidisciplinary Research Partnership "Biotechnology for a Sustainable Economy" no. 01MRB510W), the Interuniversity Attraction Poles Program (IUAP VII/29), initiated by the Belgian State, Science Policy Office, University of Leuven, and the European Research Council under the European Union's Horizon 2020 Framework Programme (ERC Grant agreement 647458). We thank Martine De Cock for proofreading the chapter.

\section{References}

1. Betti C, Vanhoutte I, Coutuer S, De Rycke R, Mishev K, Vuylsteke M, Aesaert S, Rombaut D, Gallardo R, De Smet F, Xu J, Van Lijsebettens M, Van Breusegem F, Inzé D, Rousseau F, Schymkowitz J, Russinova E (2016) Sequence-Specific protein aggregation generates defined protein knockdowns in plants. Plant Physiol 171(2):773-787

2. Tyedmers J, Mogk A, Bukau B (2010) Cellular strategies for controlling protein aggregation. Nat Rev Mol Cell Biol 11:777-788
3. Rousseau F, Serrano L, Schymkowitz JWH (2006) How evolutionary pressure against protein aggregation shaped chaperone specificity. J Mol Biol 355:1037 1047

4. Goldschmidt L, Teng PK, Riek R, Eisenberg D (2010) Identifying the amylome, proteins capable of forming amyloid like fibrils. Proc Natl Acad Sci U S A 107:3487 3492

5. Mitraki A (2010) Protein aggregation: from inclusion bodies to amyloid and biomaterials. Adv Protein Chem Struct Biol 79:89-125 
6. Ganesan A, Debulpaep M, Wilkinson H, Van Durme J, De Baets G, Jonckheere W, Ramakers M, Ivarsson Y, Zimmermann P, Van Eldere J, Schymkowitz J, Rousseau F (2014) Selectivity of aggregation-determining interactions. J Mol Biol 427:236-247

7. Fernandez Escamilla A-M, Rousseau F, Schymkowitz J, Serrano L (2004) Prediction of sequence dependent and mutational effects on the aggregation of peptides and proteins. Nat Biotechnol 22:1302 1306

8. De Baets G, Van Durme J, Rousseau F, Schymkowitz J (2014) A genome-wide sequencestructure analysis suggests aggregation gatekeepers constitute an evolutionary constrained functional class. J Mol Biol 426:2405-2412

9. Hallauer AR, Lamkey KR, White PR (1997) Registration of five inbred lines of maize: B102, B103, B104, B105, and B106. Crop Sci 37:1405-1406

10. Coussens G, Aesaert S, Verelst W, Demeulenaere $M$, De Buck $S$, Njuguna $E$, Inzé D, Van
Lijsebettens M (2012) Brachypodium distachyon promoters as efficient building blocks for transgenic research in maize. J Exp Bot 63:4263-4273

11. Voinnet O, Lederer C, Baulcombe DC (2000) A viral movement protein prevents spread of the gene silencing signal in Nicotiana benthamiana. Cell 103:157-167

12. Karimi M, Bleys A, Vanderhaeghen R, Hilson P (2007) Building blocks for plant gene assembly. Plant Physiol 145:1183-1191

13. Proost S, Van Bel M, Sterck L, Billiau K, Van Parys T, Van de Peer Y, Vandepoele K (2009) PLAZA: a comparative genomics resource to study gene and genome evolution in plants. Plant Cell 21:3718-3731

14. Bradford MM (1976) A rapid and sensitive method for the quantitation of microgram quantities of protein utilizing the principle of protein-dye binding. Anal Biochem $72: 248-254$ 